\title{
Effects of a Cholecystokinin Receptor Antagonist on Intestinal Phase of Pancreatic and Biliary Responses in Man
}

\author{
Pius Hildebrand, Christoph Beglinger, Klaus Gyr, Jan B. M. J. Jansen, Lucio C. Rovati, Matthias Zuercher, \\ Cornelis B. H. W. Lamers, Ivo. Setnikar, and Georg A. Stalder \\ Division of Gastroenterology and Department of Research, University Hospital, CH-4031 Basel, Switzerland; Department of Internal \\ Medicine, Kantonsspital, CH-4410 Liestal, Switzerland; Department of Gastroenterology-Hepatology, University Hospital, \\ NL-2333 AA Leiden, The Netherlands; and Rotta Research Laboratorium, I-20050 Monza, Italy
}

\begin{abstract}
The present study was designed (a) to characterize the activity of loxiglumide as a peripheral cholecystokinin (CCK) antagonist in healthy human subjects, and $(b)$ to determine whether CCK is a physiologic regulator of the intestinal phase of mealstimulated exocrine pancreatic and biliary secretions in man. Intravenous loxiglumide ( $22 \mu \mathrm{mol} / \mathrm{kg}$ per $\mathrm{h}$ ) was highly potent in antagonizing CCK8-induced pancreatic enzyme and bile acid secretion as well as pancreatic polypeptide release. The potency and selectivity of loxiglumide as an antagonist of CCK provides the tool for evaluating the role of CCK as a physiological mediator of meal-induced pancreatic and biliary responses in humans. Infusion of a liquid test meal into the duodenum evoked an immediate response of pancreatic enzyme and bilirubin outputs, respectively. Intravenous loxiglumide significantly inhibited the meal-induced pancreatic amylase output by $63 \%$ $(P<0.05)$, lipase output by $43 \%(P<0.05)$, and bilirubin output by 59\% $(P<0.05)$. These data suggest that $\mathrm{CCK}$ is a physiological mediator of the intestinal phase of meal-stimulated pancreatic and biliary responses. (J. Clin. Invest. 1990. 85:640-646.) CCK antagonist $\bullet$ pancreas
\end{abstract}

\section{Introduction}

Despite a large number of physiological studies on meal-stimulated pancreatic enzyme secretion in man, many crucial questions remain unanswered. For example, the physiological role of cholecystokinin (CCK), ${ }^{1}$ one of the classical intestinal hormones, has remained controversial (1-3). There appears to be no doubt that plasma CCK increases after a meal. Also, by comparing increments in plasma CCK and pancreatic trypsin secretion after a meal and after exogenous CCK, we have previously suggested that CCK could be a major stimulatory mechanism of postprandial pancreatic trypsin secretion (4). The availability of potent antagonists of CCK binding to its membrane receptor enabled us to reexamine the role of CCK

Address correspondence to Dr. Christoph Beglinger, Division of Gastroenterology, University Hospital, CH-4031 Basel, Switzerland.

Received for publication 11 January 1989 and in revised form 3 October 1989.

1. Abbreviations used in this paper: AUC, area under output curve; CCK, cholecystokinin; PEG, polyethylene glycol; PP, pancreatic polypeptide.

J. Clin. Invest.

(c) The American Society for Clinical Investigation, Inc.

0021-9738/90/03/0640/07 \$2.00

Volume 85, March 1990, 640-646 as a regulator of pancreatic and biliary secretion in man (5-12). The results support the concept that CCK is a major stimulatory mechanism of intestinal phase-stimulated pancreatic enzyme and biliary responses.

\section{Methods}

Subjects. 12 healthy male volunteers aged $22-28$ yr (mean, $24 \mathrm{yr}$ ) whose bodyweight was within $10 \%$ of their ideal value (mean, $72 \mathrm{~kg}$ ) participated in the studies. None was taking any medication or had any history of gastrointestinal or endocrine symptoms and surgery. The studies were approved by the University of Basel Human Ethical Committee on 14 July 1987, and written informed consent was obtained from each subject.

Experimental procedure. Subjects were studied after an overnight fast. The order of experiments was randomized. Pancreatic and biliary secretions were studied with the standard gastroduodenal intubation marker perfusion technique detailed elsewhere (4). In brief, a fourlumen tube was placed under fluoroscopic guidance. The gastric aspiration site was situated in the antrum for continuous gastric aspiration. Normal saline containing polyethylene glycol (PEG4000) as a nonabsorbable marker was instilled into the second portion of the duodenum in a concentration of $2 \mathrm{~g} / \mathrm{liter}$ and at $2 \mathrm{ml} / \mathrm{min}$. The duodenal contents were recovered in 15-min aliquots at the distal aspiration site near the ligamentum of Treitz.

Pharmacological characterization of loxiglumide. In this part of the study, secretin was infused intravenously for the duration of each experiment at a rate of $16.4 \mathrm{pmol} / \mathrm{kg}$ per. $\mathrm{h}$. After a $75-\mathrm{min}$ period with secretin alone, doubling doses of CCK8 (4.7-37 pmol/kg per h) were infused intravenously, each dose for $\mathbf{4 5} \mathrm{min}$. These doses have previously been shown to produce threshold to maximal pancreatic enzyme secretion $(13,14)$. In three subjects, an additional dose of CCK8 (72 pmol/ $\mathrm{kg}$ per h) was given to test whether the inhibitory effect of loxiglumide is surmountable with supramaximal doses of CCK8. On different days and in random order, either saline (control) or two different doses of loxiglumide $(3.3$ or $10 \mathrm{mg} / \mathrm{kg}$ per $\mathrm{h}$ equal to 7 and 22 $\mu \mathrm{mol} / \mathrm{kg}$ per $\mathrm{h}$ ), dissolved in $0.9 \%$ saline, were infused through an indwelling catheter in a forearm vein for the duration of the experiments (255 min).

Plasma samples were obtained in regular intervals before stimulation and during the last $15 \mathrm{~min}$ of each dose of CCK8. Blood was collected in ice-chilled EDTA tubes containing 5,000 kallikrein-inhibiting units aprotinin $/ 5 \mathrm{ml}$ blood. Samples were immediately centrifuged at $4^{\circ} \mathrm{C}$ and the plasma stored at $-20^{\circ} \mathrm{C}$ until assayed for CCK, pancreatic polypeptide (PP), and loxiglumide plasma concentrations.

To evaluate the specificity of loxiglumide, dose-response curves were performed in five subjects with graded doses of secretin ( 5 and 15 $\mathrm{pmol} / \mathrm{kg}$ per h) and bombesin (1-27 pmol/kg per h) given with concomitant infusions of loxiglumide ( $22 \mu \mathrm{mol} / \mathrm{kg}$ per $\mathrm{h}$ ) or, alternatively, saline (control). Pancreatic and biliary secretions were collected as described above. Each dose of each stimulant was given for $45 \mathrm{~min}$.

To further test the specificity of loxiglumide as a CCK antagonist against a structurally related substance such as gastrin, the effect of the compound on pentagastrin-stimulated acid secretion was studied in four healthy subjects. After a 45-min basal period, pentagastrin was 
given in graded doses $(65,260$, and $1,042 \mathrm{pmol} / \mathrm{kg}$ per $\mathrm{h})$, each given for $45 \mathrm{~min}$. The experiments were repeated with loxiglumide (22 $\mu \mathrm{mol} / \mathrm{kg}$ per h). Gastric acid secretion was measured by continuous aspiration using a double-lumen gastric tube and marker perfusion technique (PEG4000) (13).

Meal studies. After proper placement of the intestinal four-lumen tube, indwelling catheters were inserted into both cubital veins for blood sampling and infusion, respectively. After a 60 -min basal period with saline perfusion to the duodenum, a liquid test meal was perfused into the duodenum for $120 \mathrm{~min}$ at the rate of $2 \mathrm{ml} / \mathrm{min}$. This perfusion rate was used to simulate the rate of gastric emptying of a liquid test meal (7). The reflux of duodenal contents into the stomach, measured by recovery of PEG4000 in the gastric aspirate, averaged $2 \%(0-9 \%)$ of the amount infused into the duodenum. On different days, either saline (control) or an intravenous infusion of the CCK antagonist loxiglumide ( $22 \mu \mathrm{mol} / \mathrm{kg}$ per $\mathrm{h}$ ) was given throughout the experiment. Plasma samples were obtained for the determination of CCK and loxiglumide concentrations during the basal period and at regular intervals after starting the meal perfusion.

The meal consisted of $275 \mathrm{ml}$ Ensure ${ }^{\circledR}, 85 \mathrm{ml} \mathrm{H}_{2} \mathrm{O}$, and $0.72 \mathrm{~g}$ PEG4000. It had an osmolality of $300 \mathrm{mosM} /$ liter and a $\mathrm{pH}$ of 7.4. The total caloric value of the perfused meal was $184 \mathrm{kcal}$, giving a load of $3.9 \mathrm{~g}$ protein $/ \mathrm{h}, 3.1 \mathrm{~g}$ fat $/ \mathrm{h}$, and $12.3 \mathrm{~g}$ carbohydrates $/ \mathrm{h}$.

Determinations. Duodenal fluid output was measured to the next milliliter; bicarbonate concentration of duodenal juice was determined by the backtitration method (15), amylase using a commercial kit (Alpha Amylase PNP; Boehringer Mannheim GmbH, Mannheim, FRG) (16), lipase by the method of Grenner et al. (17) using a commercial kit (Behring Werke, Marburg, FRG), bile salts using 3-alphahydroxysteroid dehydrogenase (18), bilirubin spectrophotometrically (19), and PEG turbidimetrically (20). The duodenal fluid secretion for a given period was calculated as described previously (4). The recovery of the duodenal marker averaged $87 \pm 3 \%$ (mean \pm SEM), whereas the average percentage of PEG recovered from the stomach was $<2 \%$. Recoveries were similar in the different experiments and were unaffected by loxiglumide administration. Gastric fluid was measured to the next milliliter; acid concentration was determined by titration, and PEG concentration was measured turbidimetrically (20).

Assays. Plasma CCK concentrations were estimated as previously described (21) and all measurements were done with antibody T204. This antibody has been extensively characterized (22) and has been shown to bind to all carboxyl-terminal CCK peptides containing the sulfated tyrosine. The antibody shows $<2 \%$ crossreactivity to sulfated gastrins and does not bind to unsulfated forms of gastrin or structurally unrelated peptides. Furthermore, loxiglumide does not interfere with the assay. The sensitivity of the assay was $0.5 \mathrm{pmol} /$ liter plasma. The intraassay variation was $<10 \%$ at $2.6 \mathrm{pmol} / \mathrm{liter}$. All samples were assayed in the same run.

Coded plasma samples were assayed for PP concentration using previously described methods (23). The sensitivity of the assay was 2 pmol/liter plasma.

Loxiglumide concentrations were measured by HPLC according to methods described elsewhere (24). The detection limit was 0.02-0.03 $\mu \mathrm{g} / \mathrm{ml}$ plasma.

Materials. Synthetic CCK8 was purchased from Peninsula Laboratories, Inc. (Belmont, CA). The peptide was dissolved in $0.9 \%$ saline containing $0.5 \%$ human serum albumin under aseptic conditions by the University of Basel Hospital pharmacy. Vials of $20 \mu \mathrm{g} \mathrm{CCK8}$ were stored at $-20^{\circ} \mathrm{C}$. Synthetic human secretin was a kind gift of Prof. L. Moroder (Max Planck Institute, Munich, FRG). Loxiglumide was obtained from Rotta Research Laboratorium (Monza, Italy), and Ensure $^{\oplus}$ from Abbott Co. Ltd., Zug, Switzerland.

Data analysis. Data are expressed as mean \pm SEM unless stated otherwise. For each subject and each test, pancreatic and biliary responses as well as plasma hormone responses to all doses of CCK8 or to meal perfusion were calculated as area under the output curve (AUC) over basal values for bicarbonate (millimoles), lipase (milligrams), amylase (kallikrein-inhibiting units), bilirubin (milligrams), bile salts (millimoles), PP, and CCK (picomolar). Secretory outputs in response to each dose of CCK8 with and without different doses of loxiglumide were also analyzed by the following routine: For multiple comparisons of secretory responses, samples were first tested for normality by Wilk-Shapiro test and for homogeneity of variances (test of Levene). When normal distribution of data could not be rejected, data were analyzed by two-way analysis of variance. In case of significant differences, this was followed by Newman-Keuls multicomparison test for pairwise comparisons of AUCs and Dunnett multicomparison test for the comparison of the secretory responses during each dose of CCK8 with and without loxiglumide. For nonnormally distributed samples, the nonparametric Friedman test was applied. All statistical tests were used as routine in RS/1, a commercially available software package for VAX computers. The nominal level of significance was $P=0.05$.

\section{Results}

\section{Pharmacodynamics of loxiglumide}

CCK8-induced pancreatic secretion. As expected, the infusion of graded doses of CCK8 produced a dose-dependent stimulation of exocrine pancreatic secretion. The maximal amylase and lipase outputs were observed with $37 \mathrm{pmol} / \mathrm{kg}$ per h CCK8, whereas $72 \mathrm{pmol} / \mathrm{kg}$ per $\mathrm{h}(n=3)$ did not seem to further increase pancreatic enzyme output, suggesting supramaximal stimulation.

Doses of 3.3 and $10 \mathrm{mg} / \mathrm{kg}$ per $\mathrm{h}$ of loxiglumide antagonized markedly CCK8-stimulated pancreatic enzyme release (Fig. 1, Table I). The antagonism of pancreatic secretory re-

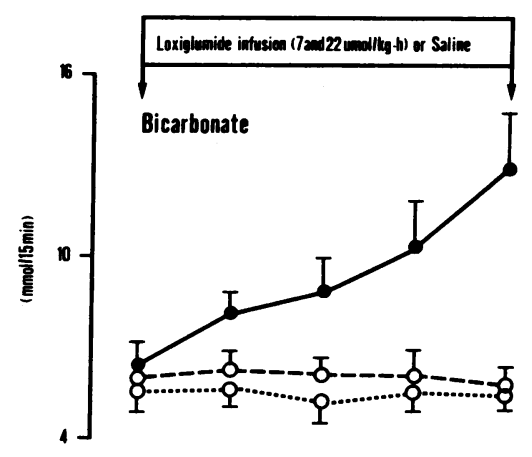

Figure 1. Effect of loxiglumide ( 7 and 22 $\mu \mathrm{mol} / \mathrm{kg}$ per $\mathrm{h}$ ) on CCK8-stimulated pan-
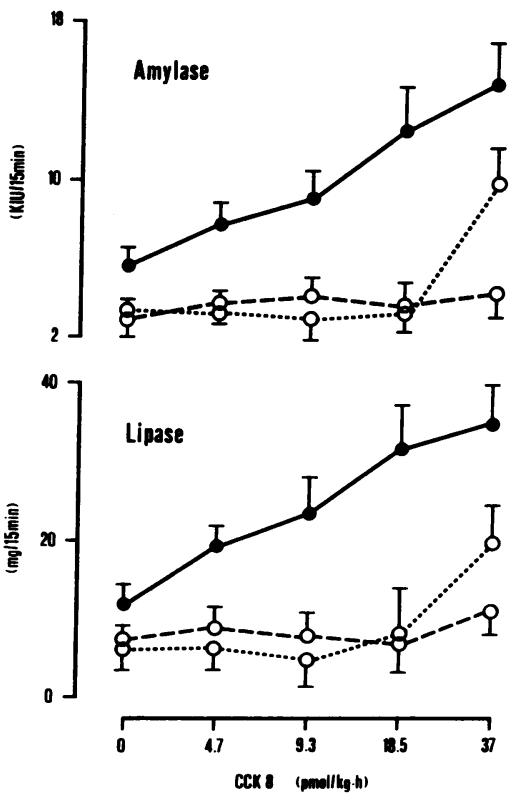
creatic lipase-, amylase-, and bicarbonate outputs in healthy subjects. Secretin was infused throughout the experiments. Data are mean \pm SEM; $n=4$ for the lower dose of loxiglumide and $n=6$ for the upper dose of loxiglumide and the control experiment. Loxiglumide significantly suppressed pancreatic lipase, amylase, and bicarbonate responses $(P$ $<0.05-P<0.01$, respectively). $\bullet, \mathrm{NaCl}$; -,$- 22 \mu \mathrm{mol} / \mathrm{kg}$ per $\mathrm{h}$ loxiglumide; $\cdots \circ \cdots, 7 \mu \mathrm{mol} / \mathrm{kg}$ per $h$ loxiglumide. 
Table I. Pancreatic Secretory Responses to Graded Doses of CCK8 With and Without Concomitant Infusion of Two Different Doses of Loxiglumide

\begin{tabular}{lllc}
\hline & \multicolumn{3}{c}{ Loxiglumide $(\mu \mathrm{mol} / \mathrm{kg}$ per $\mathrm{h})$} \\
\cline { 2 - 4 } & 0 (Control) & \multicolumn{1}{c}{7} & \multicolumn{1}{c}{22} \\
\hline Bicarbonate $(\mathrm{mmol})$ & $36.4 \pm 3.4$ & $15.7 \pm 6.3$ & $10.8 \pm 3.6^{*}$ \\
Amylase $(\mathrm{KIU})$ & $41.3 \pm 8.0$ & $23.3 \pm 9.0$ & $12.7 \pm 3.8^{*}$ \\
Lipase $(\mathrm{mg})$ & $83.6 \pm 14.3$ & $32.4 \pm 29.2$ & $18.6 \pm 15.2^{*}$
\end{tabular}

Group means \pm SEM were calculated from individual AUC above basal values to all doses of CCK8. $n=6$, except lower dose of loxiglumide, where $n=4$.

${ }^{*} P<0.01$ compared with control (saline).

sponses to CCK8 produced by the higher dose of loxiglumide was essentially complete. Both doses of loxiglumide completely antagonized the potentiating effect of CCK8 on the bicarbonate response to secretin (Fig. 1). In the three subjects who received an additional dose of CCK8 (72 pmol/kg per h), we observed a diminished inhibition of pancreatic enzyme output during the lower dose of loxiglumide ( $7 \mathrm{pmol} / \mathrm{kg}$ per $\mathrm{h}$ ), suggesting that the inhibition caused by loxiglumide was surmountable.

CCK8-induced bile acid secretion. Basal bile acid output was very low and not affected by loxiglumide. Step-doses of CCK8 induced increasing bile acid output with a maximal response obtained at a dose of $9.2 \mathrm{pmol} / \mathrm{kg}$ per $\mathrm{h}$ (Fig. 2). Both doses of loxiglumide completely blocked CCK8-stimulated bile acid secretion $(P<0.01)$.

Secretin-stimulated secretion. During infusion of saline (control), mean fasting pancreatic secretion was constant. The infusion of loxiglumide for 75 min caused a marked decrease in enzyme output, but had no significant effect on fluid and bicarbonate secretion (Fig. 3). Graded doses of secretin induced a dose-dependent increase in fluid and bicarbonate secretion, which was not affected by loxiglumide (Fig. 4).

Bombesin-stimulated secretion. Bombesin (1-27 pmol/ $\mathrm{kg}$ per h) stimulated pancreatic enzyme and bicarbonate secretion in a dose-dependent manner (Fig. 5). A dose of $22 \mu \mathrm{mol} / \mathrm{kg} \mathrm{per}$ $h$ of loxiglumide did not affect this response.

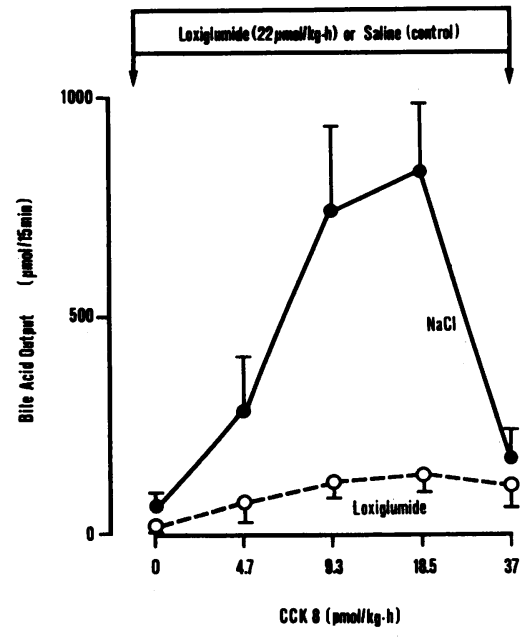

Figure 2. Effect of loxiglumide $(22 \mu \mathrm{mol} / \mathrm{kg}$ per h) on CCK8-stimulated bile acid output in six healthy subjects. Data are mean \pm SE Loxiglumide signifcantly suppressed CCK8-stimulated bile acid output $(P<0.01)$.
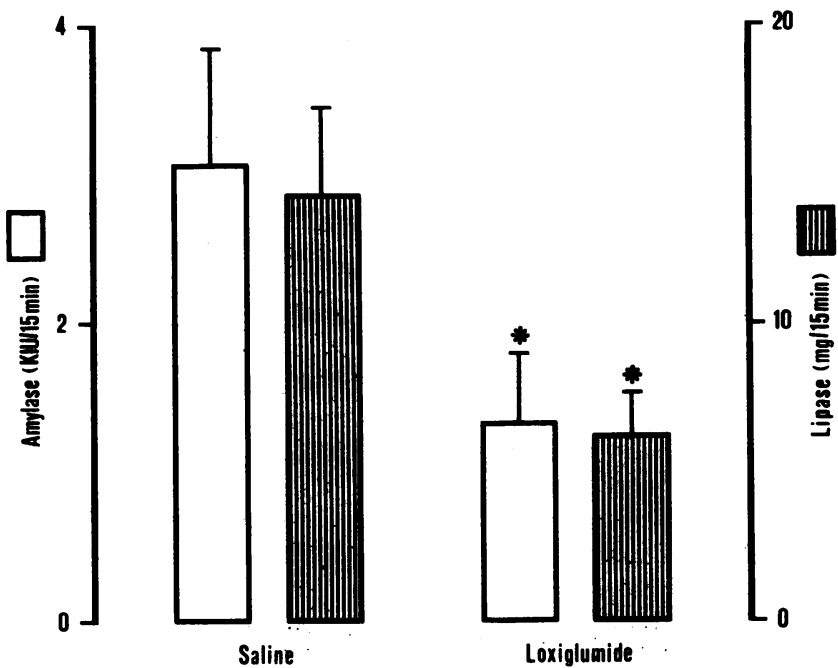

Figure 3. Effect of loxiglumide ( $22 \mu \mathrm{mol} / \mathrm{kg}$ per h) on fasting pancreatic enzyme responses in six healthy human subjects. Data are mean \pm SEM. ${ }^{*} P<0.05$.

CCK8-induced $P P$ release. CCK 8 caused a dose-dependent increase in plasma PP over basal concentrations (Table II). Loxiglumide produced a complete antagonization of the PP response to CCK8 $(P<0.01)$.

Acid responses to pentagastrin with and without loxiglumide. Intravenous pentagastrin resulted in a dose-related significant increase in gastric acid output. The administration of $22 \mu \mathrm{mol} / \mathrm{kg}$ per h loxiglumide did not significantly change the acid response to pentagastrin (Fig. 6).

Plasma CCK concentrations. Fasting plasma CCK levels were comparable in the different experiments. Increasing doses of CCK8 produced a dose-dependent increase in plasma CCK-like immunoreactivity, which was significant for the lowest dose already (Table II). Loxiglumide did not affect plasma CCK concentrations in response to graded doses of exogenous CCK.

\section{Pharmacokinetics of loxiglumide}

Infusion of loxiglumide for $4.25 \mathrm{~h}$ at the rates of 7 and 22 $\mu \mathrm{mol} / \mathrm{kg}$ per $\mathrm{h}$ produced dose-dependent plasma concentra-

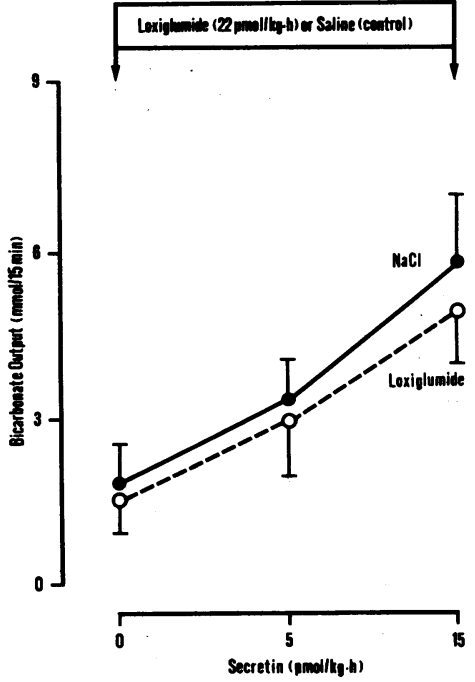

Figure 4. Effect of loxiglumide $(22 \mu \mathrm{mol} / \mathrm{kg}$ per $\mathrm{h})$ on secretin-stimulated pancreatic bicarbonate secretion in six healthy subjects. Data are mean \pm SEM. 

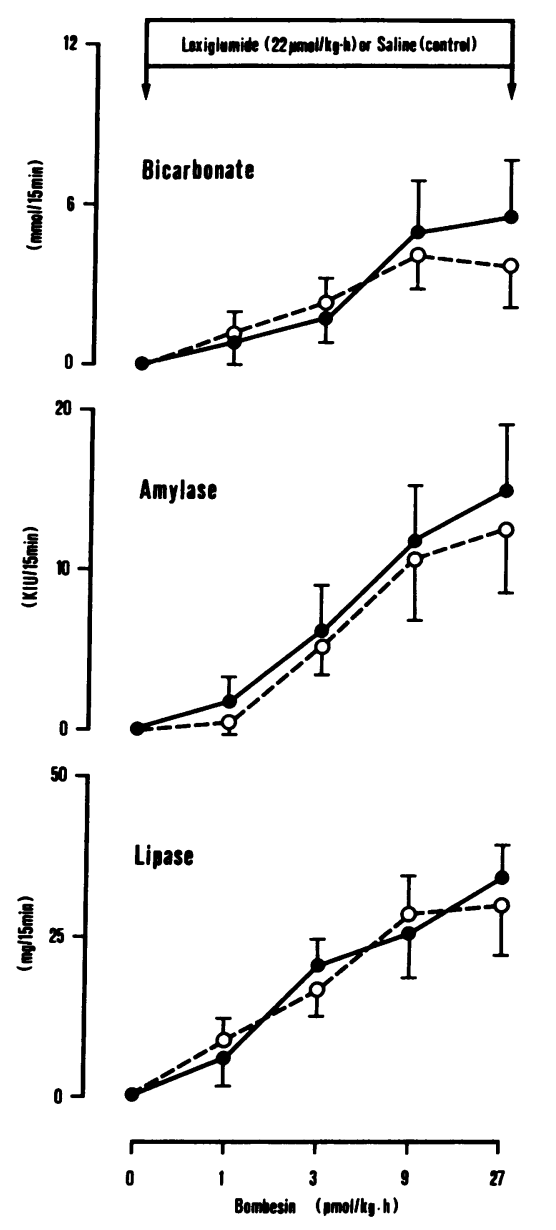

Figure 5. Effect of loxiglumide $(22 \mu \mathrm{mol} / \mathrm{kg}$ per h) on incremental pancreatic secretory responses to graded doses of bombesin in six healthy human subjects. Data are mean \pm SEM.

$\bullet, \mathrm{NaCl}$; O, loxiglumide.

tions reaching steady-state conditions after $\sim 60$ min (data not shown). No half-life determinations were done in these studies and no side effects were recorded during the experiments.

\section{Meal experiments}

Pancreatic enzyme and biliary response to test meal. Pancreatic amylase and lipase outputs increased immediately after starting the meal perfusion (Fig. 7). Loxiglumide ( $22 \mu \mathrm{mol} / \mathrm{kg}$ per $\mathrm{h}$ ), given as an intravenous infusion, antagonized mark-

Table II. Plasma CCK and PP Concentrations in Response to Graded Doses of CCK8 With and Without a Concomitant Infusion of Loxiglumide (22 $\mu \mathrm{mol} / \mathrm{kg}$ per $\mathrm{h}$ )

\begin{tabular}{|c|c|c|c|c|}
\hline \multirow[b]{2}{*}{ Dose of CCK8 } & \multicolumn{2}{|c|}{ CCK } & \multicolumn{2}{|c|}{ PP } \\
\hline & Control & Loxiglumide & Control & Loxiglumide \\
\hline$n g / k g$ per $h$ & \multicolumn{4}{|c|}{ pmol/liter } \\
\hline 0 (Basal) & $2.5 \pm 0.1$ & $2.0 \pm 0.3$ & $15.6 \pm 2.6$ & $14.4 \pm 2.4$ \\
\hline 5 & $3.8 \pm 0.3$ & $3.5 \pm 0.6$ & $24.3 \pm 6.5$ & $13.2 \pm 3.4$ \\
\hline 10 & $4.5 \pm 0.3$ & $4.6 \pm 0.5$ & $29.0 \pm 3.2$ & $12.6 \pm 1.6$ \\
\hline 20 & $7.9 \pm 0.6$ & $7.1 \pm 0.7$ & $36.1 \pm 8.5$ & $11.4 \pm 1.8$ \\
\hline 40 & $13.2 \pm 2.0$ & $12.0 \pm 1.7$ & $57.8 \pm 7.7$ & $14.5 \pm 2.0$ \\
\hline
\end{tabular}

The average of two blood samples taken at the end of each infusion period was used to calculate group means and SEM; $n=6$.

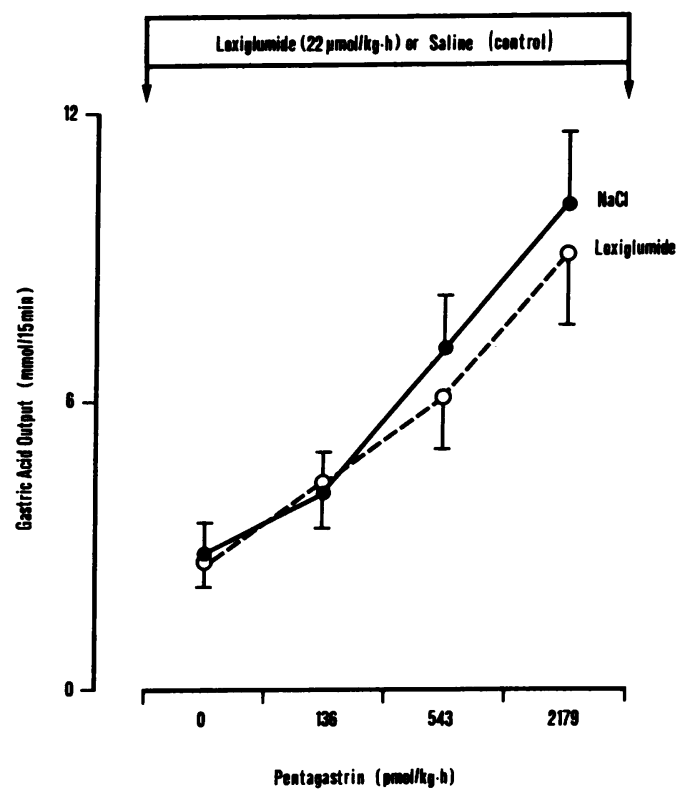

Figure 6. Effect of loxiglumide ( $22 \mu \mathrm{mol} / \mathrm{kg}$ per $\mathrm{h})$ on gastric acid output stimulated by graded doses of pentagastrin in four healthy subjects. Data are mean \pm SEM.

edly meal-stimulated pancreatic amylase and lipase outputs. The inhibition amounted to $63 \%$ for amylase and $43 \%$ for lipase output, respectively $(P<0.05)$ (Table III). The time course of bilirubin output is also given in Fig. 7. Loxiglumide significantly reduced the intraduodenal bilirubin response by
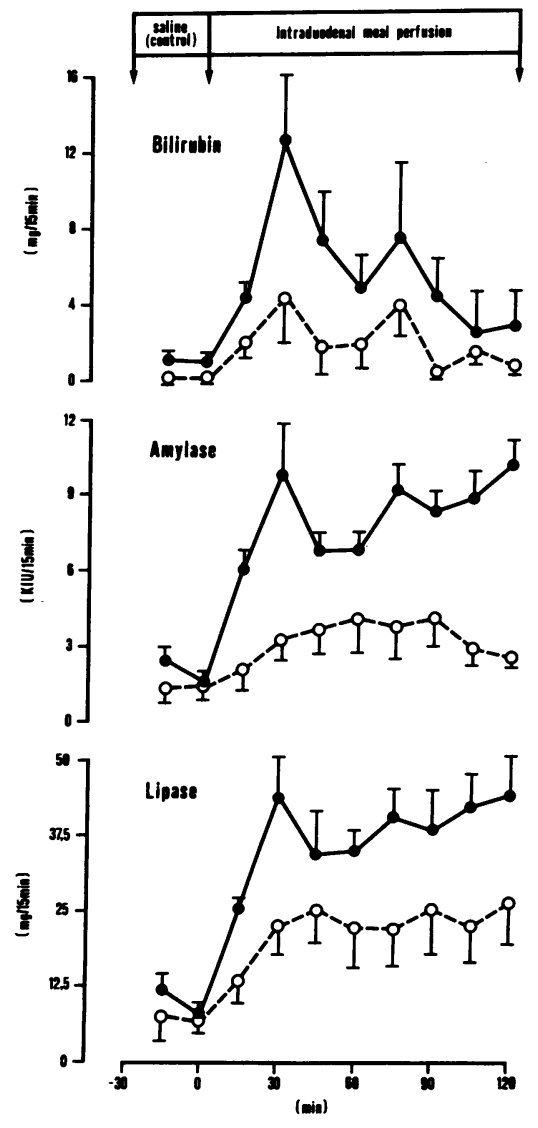

Figure 7. Effect of loxiglumide $(22 \mu \mathrm{mol} / \mathrm{kg}$ per $h)(0)$ on intraduodenally meal-stimulated pancreatic and biliary responses in six healthy subjects. Data are mean \pm SEM. $\bullet, \mathbf{N a C l}$. 
Table III. Pancreatic and Biliary Secretory Responses to Intraduodenal Test Meal Perfusion With and Without Loxiglumide in Healthy Human Subjects

\begin{tabular}{lcc}
\hline & Control (saline) & Loxiglumide $(22 \mu \mathrm{mol} / \mathrm{kg}$ per h) \\
\hline Bilirubin $(m g)$ & $39.3 \pm 11.9$ & $16.1 \pm 7.0^{*}$ \\
Amylase $(K I U)$ & $40.8 \pm 3.4$ & $15.0 \pm 3.1^{*}$ \\
Lipase $(m g)$ & $200 \pm 24$ & $113 \pm 29^{*}$ \\
\hline
\end{tabular}

AUC (over $120 \mathrm{~min}$ ) above basal values; $n=6$.

${ }^{*} P<0.05$ compared with control (saline).

59\% (Table III, $P<0.05$ ). Fluid secretion during meal perfusion reached $308 \pm 65 \mathrm{ml} / 120 \mathrm{~min}$ in control experiments and was not significantly different with the antagonist $(379 \pm 127$ $\mathrm{ml} / 120 \mathrm{~min}$ ).

Plasma CCK concentrations. Fasting plasma CCK levels were $1.8 \pm 0.1 \mathrm{pmol} / \mathrm{liter}$ for experiments both with and without loxiglumide. Perfusion of the meal into the duodenum evoked a prompt and significant increase of plasma CCK concentrations. Loxiglumide significantly augmented the CCK response to intraduodenal meal stimulation (AUC with loxiglumide was roughly four times higher compared with control; $P<0.05$ ) (Fig. 8).

Plasma PP concentrations. Loxiglumide did not affect unstimulated plasma PP concentrations. Duodenal perfusion of the test meal caused a significant increase in PP response (AUC $=4,431 \pm 1,583 \mathrm{pM} \cdot 120 \mathrm{~min}, P<0.05$ ) during saline perfusion. Loxiglumide completely suppressed $(P<0.05)$ this response $($ AUC $=614 \pm 582, P<0.05)$.

\section{Discussion}

Loxiglumide has been characterized as a new potent antagonist of CCK (8-12). In vitro studies have demonstrated higher affinity of loxiglumide for peripheral CCK receptors than for brain CCK receptors and competitive antagonization of CCK8-stimulated gallbladder contraction, pancreatic enzyme

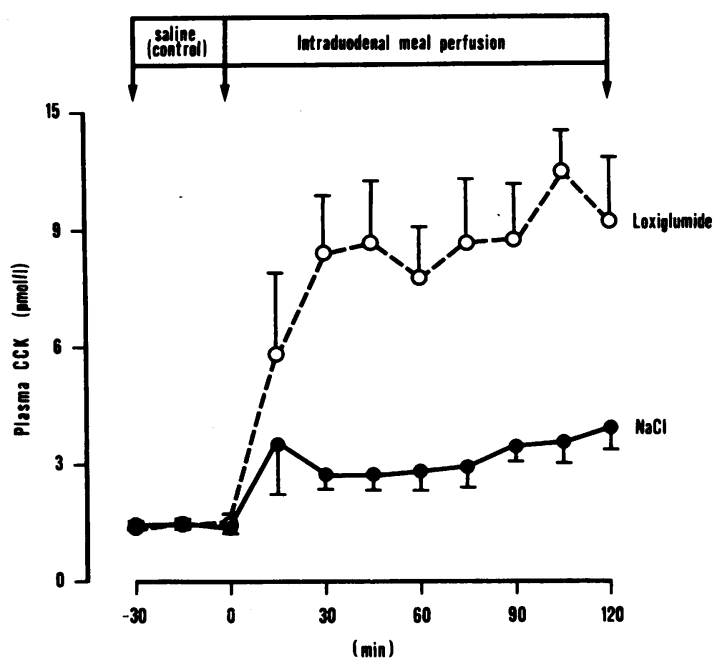

Figure 8. Plasma CCK concentrations after intraduodenal meal perfusion with and without intravenous loxiglumide ( $22 \mu \mathrm{mol} / \mathrm{kg}$ per h) in six healthy subjects. Data are mean \pm SEM. release, and smooth muscle strip contractions (8-11). It is unlikely that loxiglumide acts on postreceptor mechanisms as it does not inhibit amylase release stimulated by agents such as calcium ionophore A-23187 and 12-O-tetradecanoylphorbol13-acetate in vitro, which bypass receptor mechanisms (5). In vivo data in dog and rat demonstrate competitive-like kinetics of CCK-stimulated protein secretion $(12,25)$.

This is the first study to characterize the activity and selectivity of loxiglumide as an antagonist of CCK8 in healthy human volunteers. Here we have shown that CCK8-stimulated pancreatic enzyme and biliary secretions as well as plasma pancreatic polypeptide release can be antagonized in a dose-dependent manner, whereas pancreatic bicarbonate output stimulated by secretin, pancreatic enzyme responses to bombesin, and pentagastrin-stimulated acid secretion were unaffected by the compound. The antagonism was close to complete in the physiological dose range of CCK8. The CCK8 dose-response curve was gradually shifted to the right by increasing loxiglumide, indicating competitive-like kinetics. These data suggest that the compound is a specific antagonist of CCK in man interacting competitively with CCK receptors in the exocrine and endocrine pancreas and in the gallbladder.

CCK has a variety of biological effects upon the gastrointestinal tract. There is good evidence that circulating CCK accounts for a major fraction of postprandial pancreatic enzyme secretion and gallbladder contraction in man and animals (1). Furthermore, physiological effects on gastrointestinal motility have been suggested $(1,6,7)$. These conclusions are based on animal data obtained with other CCK antagonists and on indirect evidence obtained in humans. We have recently demonstrated that administration of loxiglumide completely inhibits postprandial gallbladder contraction in healthy human subjects, thus indicating that endogenously released CCK is a major regulator of the postprandial gallbladder response in humans (26).

The fundamental questions with regard to the physiological role of CCK as a regulator of postprandial pancreatic enzyme and biliary secretions have recently been summarized by Solomon (1): (a) Are plasma CCK levels increased after a meal? $(b)$ What proportion of the postprandial enzyme secretion is due to elevated plasma CCK? (c) Do other factors interact with CCK to augment its effect on digestive enzyme secretion?

The present study shows that a significant increase in plasma CCK is found after perfusion of a test meal to the duodenum, confirming several previous reports with oral food intake (4, 27-29). The magnitude of the postprandial CCK release amounted to $2-3 \mathrm{pmol} / \mathrm{liter}$, which is in the same range previously reported for oral meals $(4,27-29)$. Comparable plasma CCK-like concentrations were found after infusion of CCK 8 in doses $<18.5 \mathrm{pmol} / \mathrm{kg}$ per $\mathrm{h}$. These doses of CCK8 produced an increase of pancreatic amylase and lipase output, respectively, therefore indicating that postprandial concentrations of CCK-like immunoreactivity are able to stimulate exocrine pancreatic secretion. Pretreatment with the CCK antagonist loxiglumide inhibited the pancreatic enzyme responses to food stimulation by $43-63 \%$ and bilirubin output by $59 \%$. Taken together, these findings suggest that the amount of CCK released postprandially is sufficient to account for a substantial number of the pancreatic enzyme and biliary responses to intestinal meal stimulation. We interpret these data as direct proof that circulating CCK is a major stimulatory pathway of 
the intestinal phase of exocrine pancreatic and biliary responses and thus a true hormone.

Pronounced inhibitory effects have been described after atropine administration or vagotomy on exocrine pancreatic secretory responses, but not on plasma CCK release, suggesting a major role for direct cholinergic stimulation of pancreatic enzyme secretion during meal stimulation (30). The present data are not a contradiction to these observations, but are compatible with these latter results: a sustained secretory response remained after administration of the CCK antagonist loxiglumide, although all endogenous CCK should have been blocked in the study by loxiglumide. We take the residual pancreatic secretory response in response to intestinal meal stimulation observed in the blocker experiment as evidence for the existence of other stimulatory mechanisms such as cholinergic stimulation.

This study revealed that plasma CCK levels were increased three- to fourfold in the meal experiment with concomitant loxiglumide administration. Owyang and co-workers have shown that CCK release is regulated by intraduodenal trypsin, suggesting that feedback control of pancreatic enzyme secretion is operative in man (30). Thus, the reduced pancreatic enzyme response observed in the blocker experiment could induce stimulation of CCK through a positive feedback control.

The cholinergic mediation of PP release and its inhibition by atropine are well established $(31,32)$. Here, we demonstrate that loxiglumide nearly abolished intestinal phase-stimulated plasma PP release. These findings extend the previous observations with atropine $(31,32)$ and suggest that both the cholinergic and the peptidergic (CCK) system are required for a regular PP response to intestinal phase stimulation.

Several questions remain unanswered in this study. What is the contribution of CCK to the cephalic and gastric phase of pancreatic secretion? Do other factors interact with CCK to augment its effect on pancreatic enzyme secretion during the various postprandial phases? Which molecular form of CCK is predominant after meal stimulation? More information is clearly required to answer these questions.

In conclusion, the results of the present study support the concept that cholecystokinin plays a physiological role in the regulation of the intestinal phase of human pancreatic enzyme and biliary secretions after meal stimulation. We conclude that $\mathrm{CCK}$ is an important gastrointestinal hormone in human digestive physiology.

\section{Acknowledgments}

We thank Miss Sylvia Ketterer for expert technical assistance and Mrs. Carita Frei for editorial assistance and typing of the manuscript.

The study was supported in part by grants from the Swiss National Science Foundation (3.866-0.85 and 3.890-0.88).

\section{References}

1. Solomon, T. E. 1987. Control of exocrine pancreatic secretion. In Physiology of the Gastrointestinal Tract. L. R. Johnson, editor. 2nd ed. Raven Press, New York. 1173-1207.

2. Loewe, C. J., J. R. Grider, J. Gardiner, and Z. R. Vlahcevic. 1985. Selective inhibition of pentagastrin- and cholecystokinin-stimulated exocrine secretion by proglumide. Gastroenterology. 89:746-751.

3. Stubbs, R. S., and B. E. Stabile. 1985. Role of cholecystokinin in pancreatic exocrine response to intraluminal amino acids and fat. $\mathrm{Am}$. J. Physiol. 248:G347-G352.

4. Beglinger, C., M. Fried, I. Whitehouse, J. B. Jansen, C. B. Lamers, and K. Gyr. 1985. Pancreatic enzyme response to a liquid meal and to hormonal stimulation. Correlation with plasma secretin and cholecystokinin levels. J. Clin. Invest. 75:1471-1476.

5. Jensen, R. T., R. B. Murphy, M. Trampota, L. H. Schneider, S. W. Jones, J. M. Howard, and J. D. Gardner. 1985. Proglumide analogues: potent cholecystokinin receptor antagonists. Am. J. Physiol. 249:G214-G220.

6. Chang, R. S. L., V. J. Lotti, R. L. Monaghan, J. Birnbaum, E. O. Stapley, M. A. Goetz, G. Albers-Schönberg, A. A. Patchett, J. M. Liesch, O. D. Hensens, and J. P. Springer. 1985. A potent nonpeptide cholecystokinin antagonist selective for peripheral tissues isolated from Aspergillus alliaceus. Science (Wash. DC). 230:177-179.

7. Lotti, V. J., R. G. Pendleton, R. J. Gould, H. M. Hanson, R. L. S. Chang, and B. V. Clineschmidt. 1987. In vivo pharmacology of L-364,718, a new potent nonpeptide peripheral cholecystokinin antagonist. J. Pharmacol. Exp. Ther. 241:103-109.

8. Makovec, F., R. Chisté, M. Bani, L. Revel, I. Setnikar, and L. A. Rovati. 1986. New glutamic and aspartic derivatives with potent CCK-antagonist activity. Eur. J. Med. Chem. 21:9-20.

9. Makovec, F., M. Bani, R. Chisté, L. Revel, L. C. Rovati, and L. A. Rovati. 1986. Differentiation of central and peripheral cholecystokinin receptors by new glutaramic acid derivatives with cholecystokinin-antagonistic activity. Arzneim. Forsch. 36:98-102.

10. Jensen, R. T., Z. C. Zhou, R. B. Murphy, S. W. Jones, I. Setnikar, L. A. Rovati, and J. D. Gardner. Structural features of various proglumide-related cholecystokinin receptor antagonists. Am. J. Physiol. 251:G839-G846.

11. Setnikar, I., M. Bani, R. Cereda, R. Chisté, F. Makovec, M. A. Pacini, and L. Revel. 1987. Anticholecystokinin activities of loxiglumide. Arzneim. Forsch. 37:1168-1171.

12. Hildebrand, P., C. Beglinger, E. Köhler, I. Setnikar, and K. Gyr. 1987. Biological effects of a proglumide derivative as cholecystokinin antagonist in conscious dogs. Regul. Pept. 18:213-220.

13. Regan, P. T., V. L. W. Go, and E. P. DiMagno. 1980. Comparison of the effects of cholecystokinin and cholecystokinin octapeptide on pancreatic secretion, gallbladder contraction and plasma pancreatic polypeptide in man. J. Lab. Clin. Med. 96:743-748.

14. Beglinger, C., E. Köhler, G. A. Stalder, J. Jansen, and K. Gyr. 1986. What is the maximal effective dose of caerulein in stimulating pancreatic secretion in man? Digestion. 35:125-128.

15. Lagerlöf, H. O. 1942. Pancreatic function and pancreatic disease studied by means of secretin. Acta Med. Scand. Suppl. 128:1-289.

16. Rick, W., and H. Stegbauer. 1968. Zur Bestimmung der Amylaseaktivität im Harn. Fresenius Z. Anal. Chem. 243:415-416.

17. Grenner, G., G. Deutsch, R. Schmidtberger, and F. Dati. 1982. Hochempfindlicher Enzymimmunoassay zur Bestimmung von Human-Pankreas-Lipase. J. Clin. Chem. Clin. Biochem. 20:515-519.

18. Talalay, P. 1960. Enzymatic analysis of steroid hormones. Methods Biochem. Anal. 8:119-143.

19. Schellong, G., and U. Wende. 1960. A technic for standardization of methods in serum bilirubin determination. Klin. Wochenschr. 38:703-707.

20. Hydén, S. 1955. A turbidimetric method for the determination of higher polyethylene glycols in biological materials. Kungliga Lantbrukshögskolans Annaler 22:139-145.

21. Jansen, J. B. M. J., and C. B. H. W. Lamers. 1983. Radioimmunoassay of cholecystokinin in human tissue and plasma. Clin. Chim. Acta. 131:305-316.

22. Hopman, W. P. M., P. J. S. M. Kerstens, J. B. M. J. Jansen, G. Rosenbusch, and C. B. H. W. Lamers. 1985. Effect of graded physiologic doses of cholecystokinin on gallbladder contraction measured by ultrasonography: determination of threshold, dose-response relationships and comparison with intraduodenal bilirubin output. Gastroenterology. 89:1242-1247.

23. Meyer, F. D., K. Gyr, W. H. Häcki, C. Beglinger, L. Jeker, L. 
Varga, L. Kayasseh, D. Gillessen, and G. A. Stalder. 1981. The release of pancreatic polypeptide by CCK-octapeptide and some analogues in the dog. Gastroenterology. 80:742-747.

24. Setnikar, I., R. Chisté, F. Makovec, L. C. Rovati, and S. J. Warrington. 1988. Pharmacokinetics of loxiglumide after single intravenous or oral doses in man. Arzneim. Forsch. 38:716-720.

25. Niederau, M., C. Niederau, G. Strohmeyer, and J. H. Grendell. 1989. Comparative effects of CCK receptor antagonists on rat pancreatic secretion in vivo. Am. J. Physiol. 256:G150-G157.

26. Meyer, B. M., B. A. Werth, C. Beglinger, P. Hildebrand, J. B. M. J. Jansen, D. Zach, L. Rovati, and G. A. Stalder. 1989. A physiologic role for cholecystokinin as a regulator of gastrointestinal motor functions in man. Lancet. ii:12-15.

27. Byrnes, D. J., L. Henderson, T. Borody, and J. F. Rehfeld 1981. Radioimmunoassay of cholecystokinin in human plasma. Clin. Chim. Acta. 111:81-89.

28. Anagnostides, A. A., V. S. Chadwick, A. C. Selden, J. Barr, and
P. N. Maton. 1985. Human pancreatic and biliary responses to physiological concentrations of cholecystokinin octapeptide. Clin. Sci. 69:259-263.

29. Liddle, R. A., I. D. Goldfine, M. S. Rosen, R. A. Taplitz, and J. A. Williams. 1985. Cholecystokinin bioactivity in human plasma. Molecular forms, responses to feeding, and relationship to gallbladder contraction. J. Clin. Invest. 75:1144-1152.

30. Owyang, C., D. May, and D. S. Louie. 1986. Trypsin suppression of pancreatic enzyme secretion. Differential effect on cholecystokinin release and the enteropancreatic reflex. Gastroenterology. 91:637-643.

31. Adrian, T., H. Besterman, and S. Bloom. 1979. The importance of cholinergic tone in the release of pancreatic polypeptide by gut hormones in man. Life Sci. 24:1989-1994.

32. Taylor, I., M. Feldman, C. Richardson, and J. Walsh. 1978. Gastric and cephalic stimulation of human pancreatic polypeptide release. Gastroenterology. 75:432-437. 